\title{
Pavement Inertial Point Existence Analysis under Load Diversity
}

\author{
Shanqiang $\mathrm{Li}^{1,2,3, b}$, Feng $\mathrm{Liu}^{2,3, \text { a }}$ and $\mathrm{HaO} \mathrm{Li}^{2,3, \mathrm{c}}$ \\ ${ }^{1}$ Highway Institute, Chang'an University, Xi'an 710064, China \\ ${ }^{2}$ Research and Development Center on Road Transport Safety and Emergency Support Technology \\ \&Equipment, Ministry of Transport, PRC, Guangdong, Guangzhou,510420, China \\ ${ }^{3}$ Guangdong Hualu Communications Technology, Guangzhou 510420, China \\ a Corresponding author: whlfok@126.com, b41565419@qq.com, c764397461@qq.com
}

Keywords: Inertial Point; Load Diversity; Static Load; Pulse Load; Moving Load.

\begin{abstract}
Based on the original theory of the inertial point, this paper analyzed the existence of the inertial point to the rigid concrete pavement on the Winkler foundation under the pulse load and the moving load. First, according to the actual mechanical characteristics of the pavement structure, establish the finite element analysis model of the pavement structural and verify its correctness by using the Westergaard formula results. Secondly, the static load in the pavement structure model was converted to half-sine pulse load to simulate FWD load. Through analysis, there was the inertial point in the pavement structure and the maximum relative error of the inertial point distance and the deflection of the pavement structural was about $0.7 \%$ and $0.2 \%$ under the static load and the pulse load. Finally, by using the method of the moving load belt, the finite element model of the pavement structure was applied to different the speed moving load and proved that the pavement structure still exist the inertial point. The speed of the moving load and the pavement thickness had a greater impact on it. The results show that there was the inertial point to the rigid concrete pavement on the Winkler foundation under the static load, the pulse load and the moving load. Analysis results provide some guidance to apply the inertial point theory to back-calculation of the pavement structure parameters based on the moving load.
\end{abstract}

\section{Introduction}

With the passage of time, the cement concrete pavement in use process would appear more or less disease, therefore, many scholars begin to pay close attention to the residual life calculation problem of the cement concrete pavement. But the calculation of the residual life of the pavement inevitably involved the back-calculation of the pavement elastic modulus and the foundation reaction modulus. At present, the main back-calculation method of the pavement structure were chart method, the regression formula method, iterative method, neural network, database search method and genetic algorithm, and so on. But all kinds of methods can't solve the problem of initial value and local convergence, uniqueness of solution and the rationality of the result ${ }^{1}$. In 2000, Prof. Sun Lijun from Tongji University and Prof. Yoshitaka Hachiya from the Institute of Harbor Technology of the Ministry of Transport of Japan jointly proposed a new method to solve the back-calculation program of the pavement structure--Inertia Deflection Method (IDM) ${ }^{2,3}$. In this method, the two basic parameters $E$ (elastic modulus of surface layer) and $k$ (the foundation response modulus) of the pavement structure back-analysis were solved independently. This avoided the mutual interference between the two and would greatly improve the back-calculation accuracy of the pavement structure.

According to the relevant literature ${ }^{2}$, when the thickness of the pavement layer was constant and the foundation reaction modulus was constant and the load was the same, the surface layer modulus was larger, then the deflection basin curve was more flat. Near the load, the deflection was small, and the deflection was relatively large from the load. In contrast, the surface layer modulus was lower, then the deflection basin curve was steep. Near the load, the deflection was large, and the deflection was relatively small from the load. The two curve must intersect at a point that had nothing to do with 
the modulus of the pavement surface layer. This point was known as the inertial point. The distance from the load center was the inertial point distance $\left(R_{\mathrm{c}}\right)$. The deflection at the inertial point was called inertial point deflection $\left(D_{\mathrm{c}}\right)$ (Fig. 1$)$.

With the application of the laser technology in road test, the rolling wheel deflectometer (RWD) ${ }^{4}$ came into being (Fig. 2). RWD was an apparatus which applied a load to a road surface by a vehicle itself with a certain moving speed and then detected a dynamic deflection response of a road surface by a laser detecting device. The RWD more corresponded to actual fact. But the original inertial deflection method was a regression analysis method based on the analysis of the static load. In view of this, this paper would study the existence of the inertial point of the pavement structure under the action of the pulse load and the moving load and lay the foundation for the application of the inertial point theory in the RWD back-calculation.

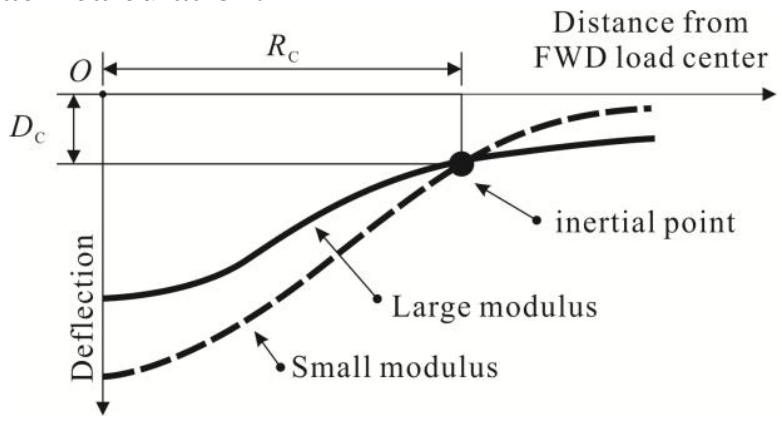

Figure 1. Deflection Basin and Its Intersection deflectometer (RWD)

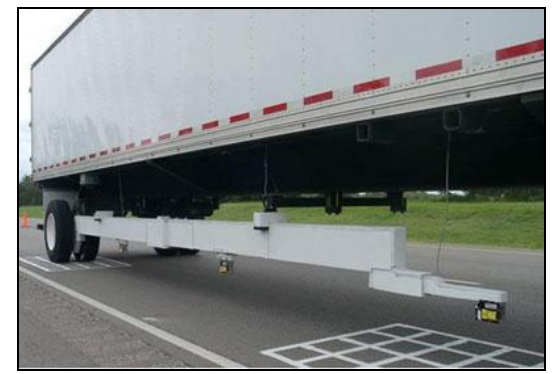

Figure 2. The rolling wheel Diagram Corresponding to Different Modulus

\section{3D Pavement Mechanics Model}

\subsection{Fundamental Assumption}

When carrying out three-dimensional mechanical analysis of the pavement structure, the following basic assumptions were usually made:

(1)The surface layer and the soil-based materials were assumed to be linear elastic materials, and they were consistent with the general Hooke theorem.

(2)The thickness of each structural layer of the pavement structure was limited and infinite in the horizontal direction. According to the relevant literature ${ }^{3}$, for the pavement static mechanical properties analysis, the soil thickness was greater than 6 meters, for the pavement dynamic mechanical analysis, the soil thickness was greater than 12 meters, the actual measured value and the theoretical analysis value was close to basically meet the calculation requirements.

(3)There was no slip between the structural layers of the pavement.

(4)The stress, strain and displacement of the pavement structure, which were perpendicular to the road surface, were zero in the infinite distance from the load and infinite depth of the pavement structure.

\subsection{Three Dimensional Finite Element Model}

Highway and airport pavement was more regular rectangular plate or square plate, so the BLOCK command in ANSYS was used to establish the finite element model of the road surface structure. The mesh model of the pavement structure was divided by SOLID45 unit. The foundation was usually simplified to three kinds of model: the Winkler foundation model, the elastic half-space foundation model and the elastic layered system model. In ANSYS analysis, the spring element COMBIN14 or 
LINK10 element were used to establish the Winkler foundation model. Fig 3 was a cross-sectional view of the pavement structure and the pavement structure parameters. Fig. 4 was the finite element model of the whole pavement structure after the mesh division was completed.

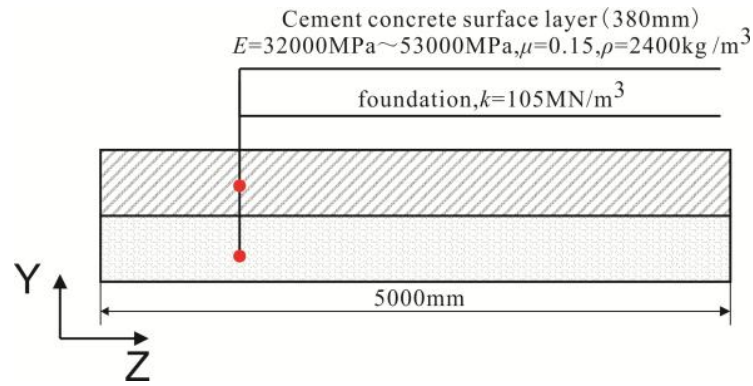

Figure 3. Transverse section of pavement structure

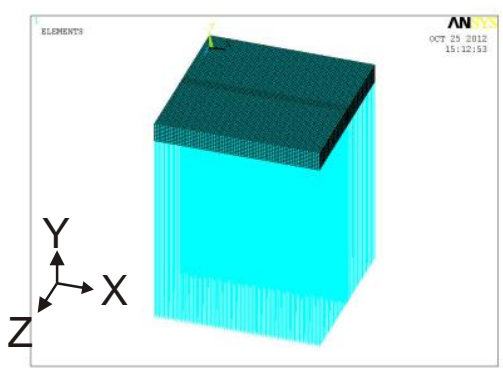

Figure 4. ANSYS pavement model

In three dimensional finite element analysis of the pavement structure, the constraint conditions of the model can be assumed to be the fixed constraint of node's displacement on the bottom of the Winkler foundation, and the four sides of the slab were bound to the normal direction of displacement ${ }^{5,6}$.

The load was divided into the static load, the impulse load and the moving load. In the existence analysis of the pavement structure inertial point, the half-sine wave function was applied to the ANSYS model with a peak pulse load of and a 30ms loading time ${ }^{7}$ (Table 1). The maximum value of the pulse load was taken as the static load. The static load and the pulse load were applied to the middle of the track panel (Fig. 6). In order to facilitate the mesh division, the circular surface was simplified as a rectangular surface according to the principle of equivalent stress $^{8}$.

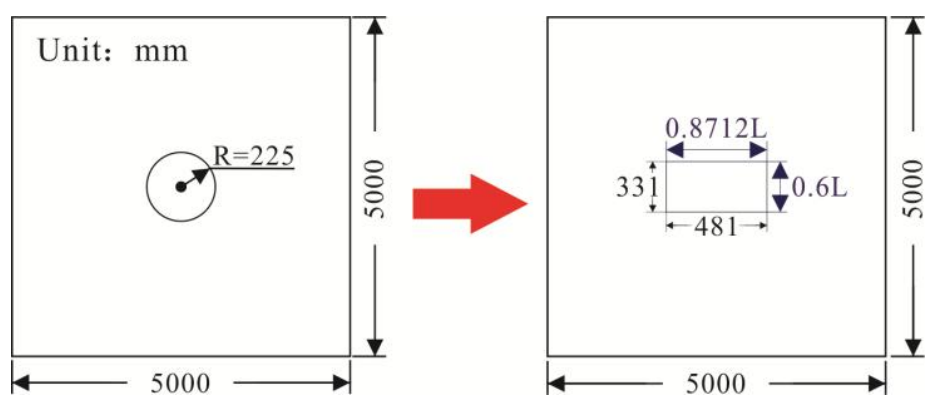

Figure 5. Load application plan

Table 1 . FWD load time history data

\begin{tabular}{|c|c|c|c|c|c|c|c|c|c|}
\hline Time $/ \mathrm{ms}$ & 0 & 1 & 3 & 5 & 7 & 9 & 11 & 13 & 15 \\
\hline Load/kPa & 0 & 104.5 & 309.0 & 500.0 & 669.1 & 809.0 & 913.5 & 978.1 & 1000.0 \\
\hline
\end{tabular}

\subsection{Verification of the Finite Element Model}

According to the Westergaard approach, when the load was applied to the middle of the road panel, the maximum bending stress (formula 1) appeared at the center of the load at the bottom of the plate, and the maximum deflection appeared at the center of the load at the top of the plate (formula 2). Taking the 32000MPa elastic modulus of the surface layer as an example, when the plate had the role of a uniform load of $1 \mathrm{MPa}$, as shown in Table 2, the maximum error of the bending stress calculated was $0.1491 \mathrm{MPa}$ and the maximum error of the deflection was $2.1 \mu \mathrm{m}$ by using the finite element method under the static load. Therefore, the ANSYS finite element model was correct and feasible for the calculation analysis of the pavement structure deflection.

$$
\begin{gathered}
\sigma=1.1 \times(1+\mu)\left(\lg \frac{l}{b}+0.2673\right) \frac{P}{h^{2}} \\
W_{\max }=\frac{P l^{2}}{8 D} \\
\mathrm{~b}=\mathrm{a}(\mathrm{a} \geq 1.724 \mathrm{~h})
\end{gathered}
$$




$$
b=\sqrt{1.6 a^{2}+h^{2}}-0.675 h(\mathrm{a}<1.724 \mathrm{~h})
$$

Where, $\sigma$-Maximum bending stress in plate, $\mathrm{MPa} ; P$-The resultant force in the plate, $\mathrm{MN}$; $h$ - The cement concrete pavement surface thickness, $\mathrm{m} ; \mu$-The Poisson's ratio of the cement concrete, $\mu=0.15 ; b$-The Equivalent radius of the load acting area, $\mathrm{m}$; $a$-Tire Grounding Area Equivalent Circle Radius, m; $D$-Road panel bending stiffness, $D=E h^{3} / 12\left(1-\mu^{2}\right), \mathrm{m} ; l$ - Relative Stiffness Radius of Plate on Winkler Foundation, m.

Table 2. The Center point deflection of the plate top and the bending stress of the driving direction of the plate bottom under the action of the static load and the impulse load

\begin{tabular}{|c|c|c|c|c|c|c|c|c|c|}
\hline \multicolumn{2}{|c|}{$\begin{array}{l}\text { the elastic modulus } \\
\text { of the surface layer } \\
\text { plate } / \mathrm{MPa}\end{array}$} & \multicolumn{2}{|c|}{32000} & \multicolumn{2}{|c|}{38000} & \multicolumn{2}{|c|}{44000} & \multicolumn{2}{|c|}{53000} \\
\hline \multirow{5}{*}{$\begin{array}{l}\text { Deflection } \\
/ \mu \mathrm{m}\end{array}$} & \multirow{2}{*}{ W } & \multicolumn{2}{|c|}{1} & \multicolumn{2}{|c|}{1} & \multicolumn{2}{|c|}{1} & \multicolumn{2}{|c|}{1} \\
\hline & & \multicolumn{2}{|c|}{-158.57} & \multicolumn{2}{|c|}{-145.60} & \multicolumn{2}{|c|}{-135.24} & \multicolumn{2}{|c|}{-123.21} \\
\hline & \multirow[b]{2}{*}{$\mathrm{F}$} & 1 & 2 & 1 & 2 & 1 & 2 & 1 & 2 \\
\hline & & -156.47 & -156.68 & -143.27 & -143.49 & -133.29 & -133.52 & -122.17 & -122.41 \\
\hline & $\begin{array}{c}\text { Relative } \\
\text { error }\end{array}$ & $1.32 \%$ & $1.19 \%$ & $1.60 \%$ & $1.45 \%$ & $1.44 \%$ & $1.27 \%$ & $0.84 \%$ & $0.65 \%$ \\
\hline \multirow{5}{*}{$\begin{array}{l}\text { Stress } \\
/ \mathrm{MPa}\end{array}$} & \multirow{2}{*}{ W } & \multirow{2}{*}{\multicolumn{2}{|c|}{$\frac{1}{1.347}$}} & \multicolumn{2}{|c|}{$\frac{1}{1373}$} & \multicolumn{2}{|c|}{1} & \multicolumn{2}{|c|}{1} \\
\hline & & & & \multicolumn{2}{|c|}{1.373} & \multicolumn{2}{|c|}{1.395} & \multicolumn{2}{|c|}{1.423} \\
\hline & \multirow[b]{2}{*}{$\mathrm{F}$} & \multicolumn{2}{|c|}{1.347} & 1 & 2 & 1 & 2 & 1 & 2 \\
\hline & & 1.1979 & 1.1967 & 1.2125 & 1.2112 & 1.2238 & 1.2225 & 1.2365 & 1.2352 \\
\hline & $\begin{array}{c}\text { Relative } \\
\text { error }\end{array}$ & $11.07 \%$ & $11.16 \%$ & $11.69 \%$ & $11.78 \%$ & $12.27 \%$ & $12.37 \%$ & $13.11 \%$ & $13.20 \%$ \\
\hline
\end{tabular}

Where, 1- The static load effect; 2- The impulse load effect; W-Westergaard formula method; F-The finite element method.

\section{Calculation of the inertial point under THE static load and THE impulsive load}

Through the finite element model analysis, the author drew a conclusion that the deflection basin curve under the action of the static load and the pulse load was obtained from the Fig. 6 and Fig. 7. According to the literature 3 and figure 7, the static load, the surface layer plate thickness and the foundation reaction modulus were constant, a series of deflection curves could be obtained by changing the elastic modulus of the surface layer plate. This set of curves intersected at points (1621.6,-66.81). This was the inertia point. From figure 8, when the $t$ was $15 \mathrm{~ms}$, the each deflection curves of the pavement structure intersected at the point $(1633.5,-66.67)$ under the influence of the pulse load. Therefore, the pavement plate structure under the pulse load still existed the inertial point, and under this pulse load the inertial point and the static load inertial point was very close, as shown in table 3 .

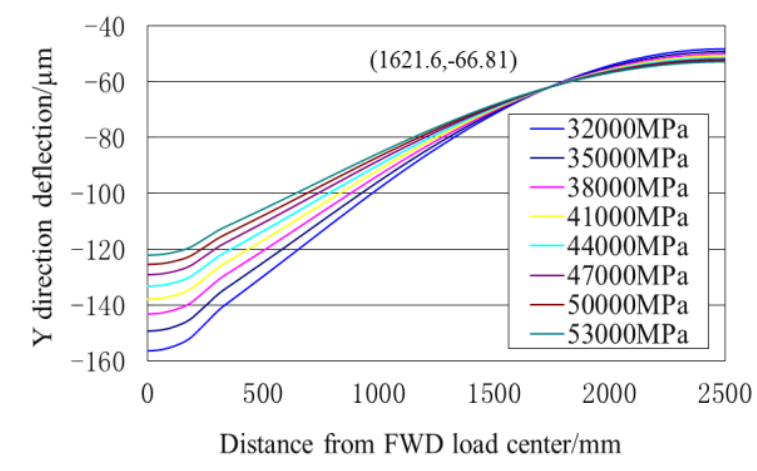

Figure 6. The inertial point of the pavement structure under the static load

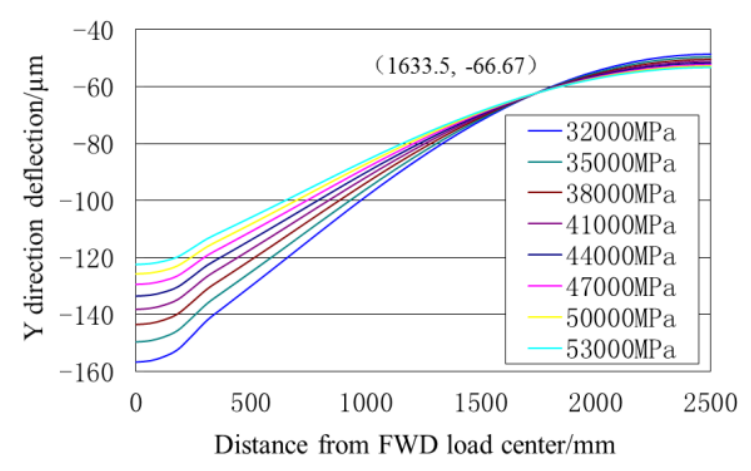

Figure 7. The inertial point of the pavement structure under the pulse load $(\mathrm{t}=15 \mathrm{~ms})$ 
Table 3. The inertial point distance and the inertial point deflection of the pavement structure $(5 \mathrm{~m} \times 5 \mathrm{~m})$

\begin{tabular}{|c|c|c|c|c|}
\hline $\begin{array}{c}\text { Calculation } \\
\text { method }\end{array}$ & $\begin{array}{c}\text { The inertial point } \\
\text { parameters }\end{array}$ & The static load & The pulse load & Relative error \\
\hline $\begin{array}{c}\text { Inertial } \\
\text { deflection } \\
\text { method }\end{array}$ & $R_{\mathrm{C}} / \mathrm{mm}$ & 1760.2 & - & - \\
\cline { 2 - 3 } & $D_{\mathrm{C}} / \mu \mathrm{m}$ & -69.15 & 1633.5 & $0.7 \%$ \\
\hline $\begin{array}{c}\text { Finite element } \\
\text { method }\end{array}$ & $R_{\mathrm{C}} / \mathrm{mm}$ & 1621.6 & -66.67 & $0.2 \%$ \\
\cline { 2 - 5 }
\end{tabular}

\section{Calculation of inertia point under the moving load}

According to the motion differential equation (5) of viscoelastic Winkler foundation plate under moving load, the deflection of the viscoelastic Winkler foundation plate under the moving load was related to the vehicle speed, the foundation damping and the thickness, density and Poisson ratio of the pavement. In this paper, only the influence of the different vehicle speed and the thickness of the pavement slab on the inertia point parameters of the pavement slab was analyzed ${ }^{9}$.

$$
D\left(\frac{\partial^{4} w}{\partial x^{4}}+2 \frac{\partial^{4} w}{\partial^{2} x \partial^{2} y}+\frac{\partial^{4} w}{\partial y^{4}}\right)+\mu w+\eta \frac{\partial w}{\partial t}+\rho h \frac{\partial^{2} w}{\partial t^{2}}=F(x, y, t)
$$

Where, $D$ - The flexural rigidity of the plate , $D=E h^{3} / 12\left(1-\mu^{2}\right) ; E$ - The elastic modulus of the plate; $h$-The thickness of the plate; $\rho$-The density of the plate; $\mu$-The Poisson's ratio of the plate; $\mu$-The foundation reaction modulus; $\eta$-The foundation damping.

\subsection{The application of moving load and calculation data extraction}

In ANSYS analysis, the moving load was analyzed by using the method of Moving load belt. That is, every time the area occupied by the tires moved forward a grid (as shown in Figure 8), until the wheel moving load moved out of the pavement panel. The vehicle moving load was simplified to the $1 \mathrm{MPa}$ uniform load and imposed on the model.

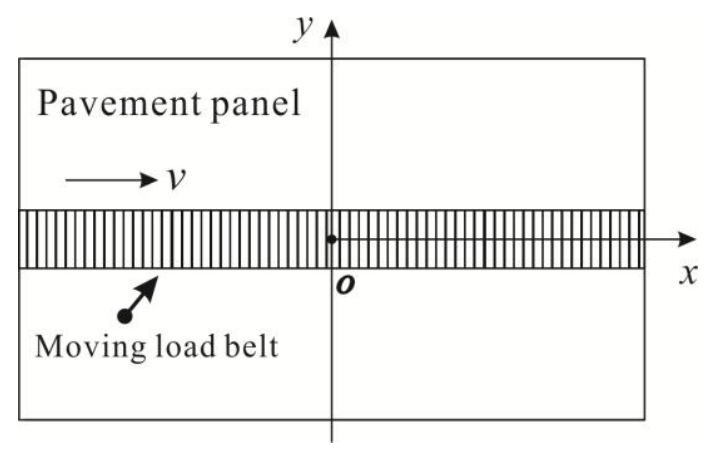

Figure 8. Moving load belt

\subsection{Influence Analysis of Vehicle Speed on the inert point parameters}

In this paper, the influence of vehicle speed on the inertia point parameters of road panel was analyzed by selecting the partial velocity points in $70 \mathrm{~km} / \mathrm{h} \sim 50 \mathrm{~km} / \mathrm{h}$. The analysis results were shown in Figure 9 and figure 10. Fig. 9 shows the deflection curve of the pavement structure under different vehicle speed, different surface elastic modulus and the same foundation reaction modulus. From the analysis results of figure 9, the rigid cement concrete pavement structure still had a small area independent of the elastic modulus of the surface layer under the action of the different moving loads in the same way as the static load acting on the slab structure. The width of this region was about 10 $\mathrm{cm}$. Therefore, the region could be reduced to a point according to the principle of the inertia point determination. It could be called a dynamic inertia. With the increase of vehicle speed, on the left side of the dynamic inertia point, the absolute value of the deflection basin curve was reduced for the deflection basin curve of the same elastic modulus. In contrast, at the right side of the dynamic inertia 
point, the absolute value of the deflection basin curve was increasing. And from the analysis of figure 10 , with the increase of the moving load velocity, the distance of the inertia point and the deflection of the inertia point all show a decreasing trend. The parameter values of the inertia point at different vehicle speed change greatly. Therefore, the velocity had a great influence on the inertia point parameters.

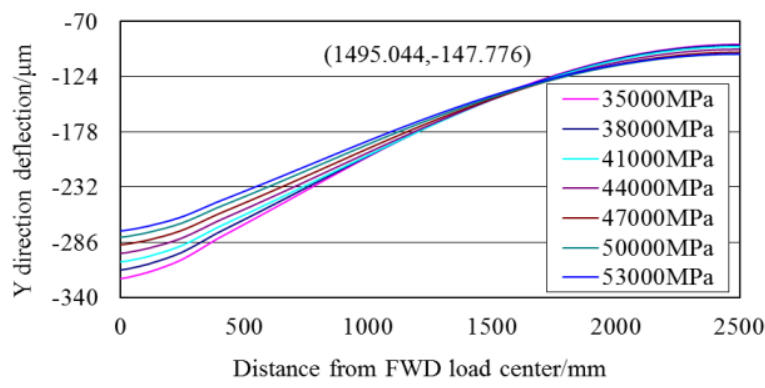

(a) $\mathrm{v}=50 \mathrm{~km} / \mathrm{h}$

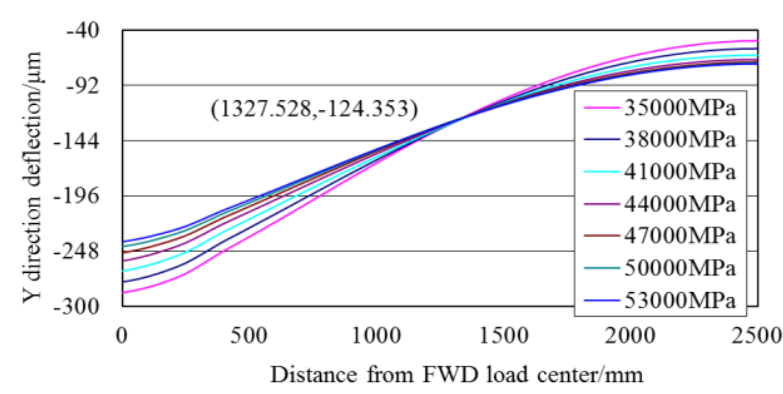

(c) $\mathrm{v}=60 \mathrm{~km} / \mathrm{h}$

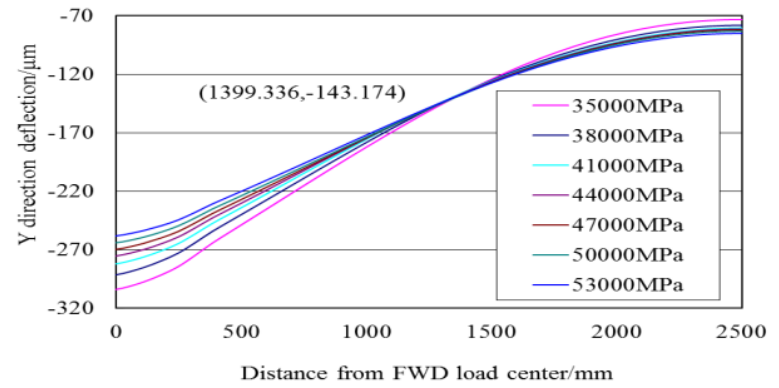

(b) $\mathrm{v}=55 \mathrm{~km} / \mathrm{h}$

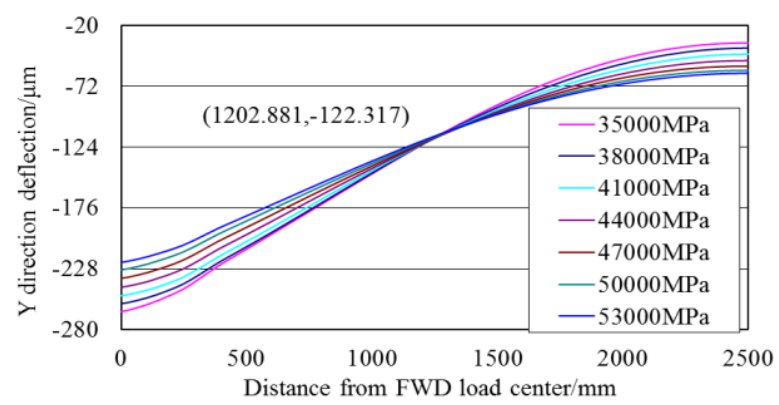

(d) $\mathrm{v}=65 \mathrm{~km} / \mathrm{h}$

Figure 9. The deflection basin curves under the different vehicle speed and the different surface plate elastic modulus
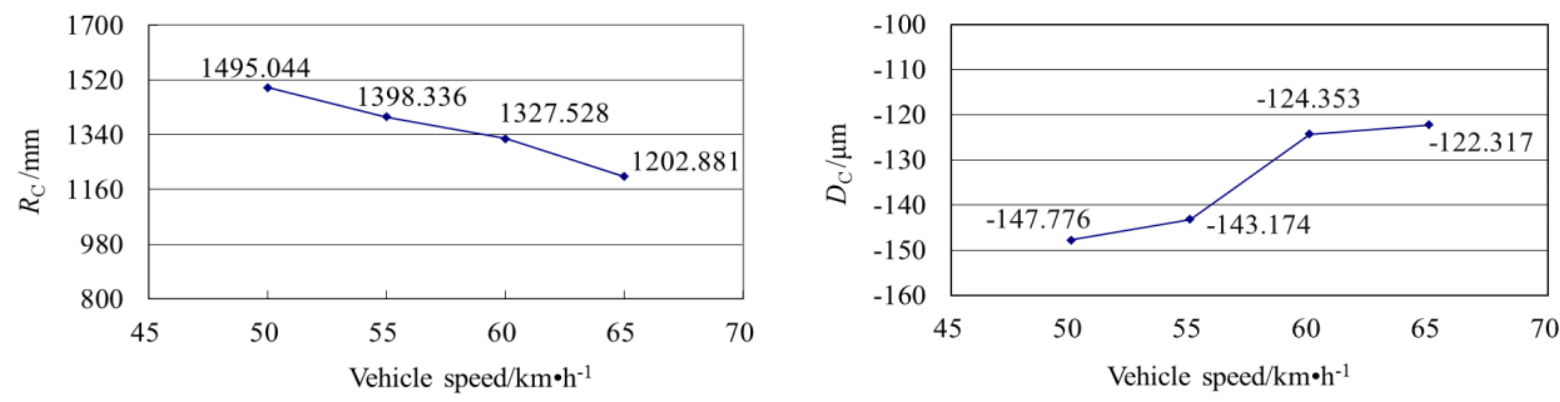

Figure 10. The curve of the inertial point parameters with vehicle speed variation

\subsection{Influence Analysis of surfacing board thickness on the inert point parameters}

According to the literature 3, under the static load, the inertia point parameters of the pavement slab structure were greatly affected by the pavement surface layer thickness. In general, as the thickness of the track pavement increased, the distance of the inert point increased and the deflection of the inert point decreased. Under the static load, the increase of the thickness of the surface layer mean the improvement of the overall rigidity of the pavement slab. Therefore, the deflection value of the plate center would be reduced, and the effect of the load on the plate would be further. From Fig. 12 , when the moving load moved at the speed of $60 \mathrm{~km} / \mathrm{h}$, the deflection value at the center point $\mathrm{O}$ of the pavement panel structure decreased with the increase of the plate thickness under the same elasticity modulus of the surface layer board. The deflection value of the pavement panel increased with the increase of the plate thickness. Therefore, the distance of the inertia point of the pavement slab structure increased with the increase of the thickness of the plate, while the inertia point 
deflection decreased with the increase of the plate thickness, as shown in Fig. 13. The thickness of the surface layer had a great influence on the inertia point parameters.

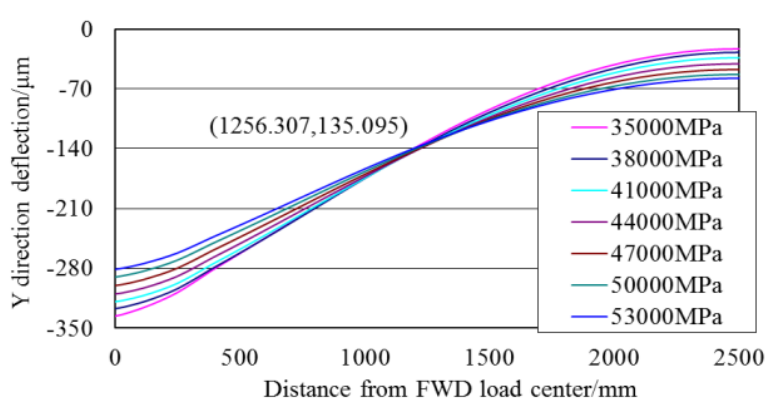

(a) $\mathrm{h}=35 \mathrm{~cm}$

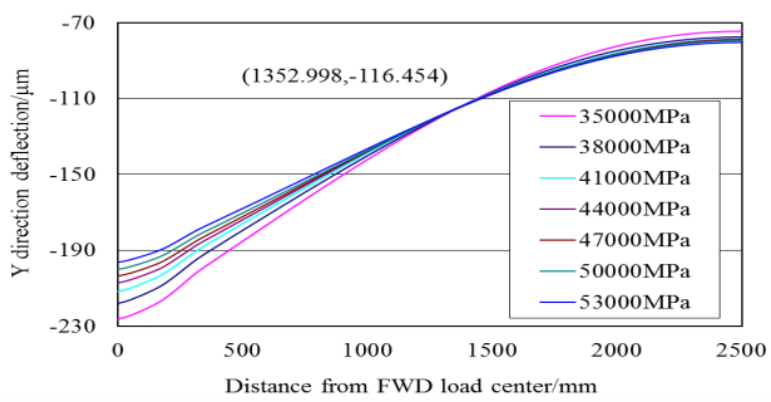

(c) $\mathrm{h}=43 \mathrm{~cm}$

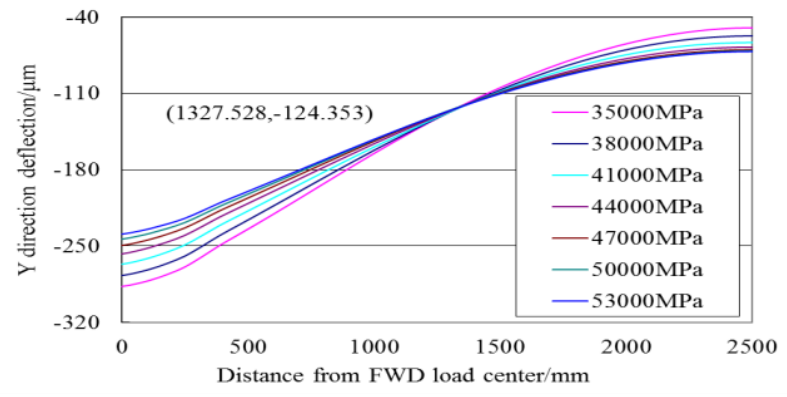

(b) $\mathrm{h}=38 \mathrm{~cm}$

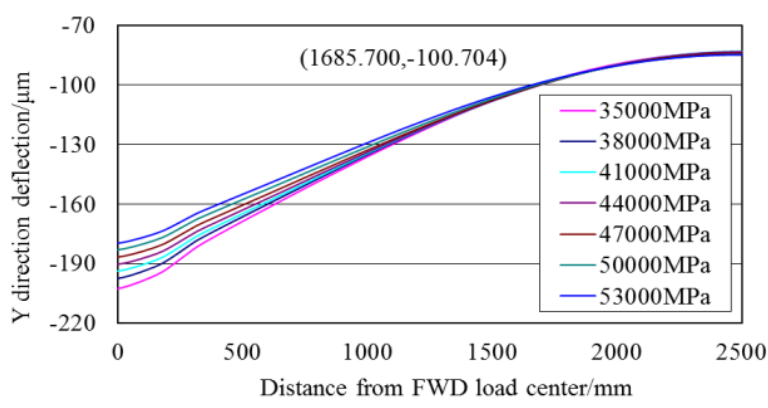

(d) $\mathrm{h}=48 \mathrm{~cm}$

Figure 11. The curve of the inertial point parameters with vehicle speed variation
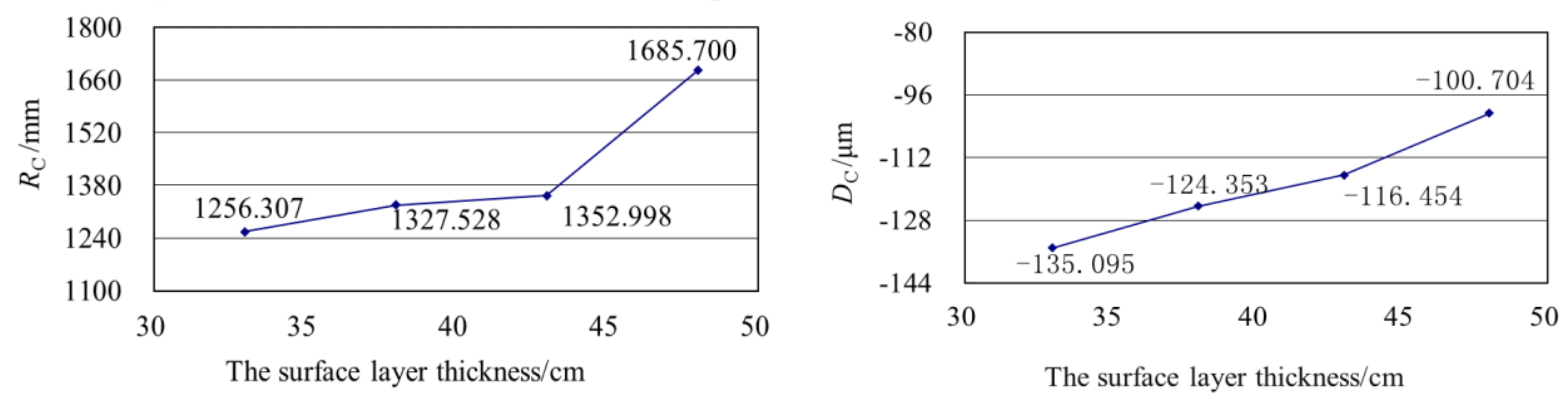

Figure 12. The curve of the inertial point parameters with the surface layer thickness

\section{Conclusion}

Based on the Westergaard formula and the differential equation of the plate movement, a large number of finite element analysis of the rigid concrete plate on the Winkler foundation can be concluded as follows:

(1) Under the static load and the pulse load, the pavement panel had the inertia point, and both the inertia point distance and the inertia point deflection were close to each other.

(2) Under the moving load, the inertia point of the pavement plate still existed. Under the moving load, the thickness of the surface layer, Poisson's ratio, the density, the foundation damping and the speed of the vehicle would have an effect on the deflection of the pavement. From the analysis results, the thickness of the surface layer and the driving speed of the vehicle to the inertia point parameters (i.e., the inertia point distance $\mathrm{R}_{\mathrm{C}}$ and the inertia point deflection $\mathrm{D}_{\mathrm{C}}$ ) were greatly influenced. Based on the dynamic inertia point parameter regression analysis, it was not negligible.

\section{Acknowledgments}

The authors appreciate the support of the science and technology project of Guangdong Provincial Communications Department (Project number: Science and technology -2012-02-011). 


\section{References}

[1] Xudong Cha. (2005). "The Back-calculation Method Review of Pavement Structure Layer Modulus". Journal of Traffic and Transportation Engineering, 33(8), pp. 1041-1046.

[2] Lijun Sun, Yoshitaka Hachiya and Zukang Yao. (2000). "A New Method for Back-calculating the Modulus of Cement Concrete Pavement-- Inertia deflection method". China Civil Engineering Journal, 33(1), pp. 83-87.

[3] Feng Liu, "Studies on Analysis of Airfield Pavement and Its Application into Structural Back-calculation," Ph.D. thesis, Wuhan University of Technology, 2015.

[4] Elseifi, M., Dasari, K. and Gaspard, K.. (2013). "Development of the Triangular Model for Pavement Evaluation Using the Rolling Wheel Deflectometer". Journal of Transportation Engineering, 139(3), pp. 313-320.

[5] Shaopu Yang, Liqun Chen and Shaohua Li. (2012). Study on Vehicle - Road Coupling System Dynamics, Science Press, Beijin.

[6] Chunfeng Yang, Lu Liu. (2000). "Dynamic Response Analysis of Cement Concrete Pavement under Different Vehicle Speeds". Journal of Hebei University Technology, 39(3), pp. 112-115.

[7] Enhui Yang, Yanjun Qiu and Xin Jiang. (2008). "The Inertial Point Theory of Deflection Basin Based on Finite Element". Journal of Chongqing Jiaotong University (Natural Science Edition), 27(2), pp. 232-235.

[8] Yangxian Huang. (1998). Pavement analysis and design, China Communications Press, Beijin.

[9] Yun Hou, Siping Sun and Zhongyin Guo. (2005). "Influence Analysis of Parameters of Rigid Pavement Response under Moving Load". Journal of Tongji University (Natural Science Edition), 31(1), pp. 83-87. 